\title{
Conquista da terra e civilização do gentio: o fenômeno imioratório italiano no Rio Grande do Sul
}

Luís Fernando Beneduzi*

\begin{abstract}
Resumo. Neste estudo, busca-se discutir as construções imagéticas de civilizador que se constituíram enquanto imaginário da imigração italiana no Rio Grande do Sul. Trabalha-se, especificamente, com o mito da fronteira que, relacionado com a imigração italiana, apresenta a figura de um imigrante laborioso e peça chave no desenvolvimento do estado. Para dialogar com essas representações, utilizam-se três níveis de documentação: a literatura católica sobre a imigração - por meio da obra Nanetto Pipetta, publicada pelo Staffetta Riograndense, da canção símbolo da imigração Mérica, Mérica e do livro comemorativo dos cinqüenta anos da imigração e colonização italiana no Rio grande do Sul. Entende-se, então, que essa imagem construída a partir de contatos com nacionais e outros europeus - embora sendo uma leitura étnica do real - conseguiu colocar-se como verdade sobre o real acontecido, obliterando a diversidade e multiplicidade das relações ao interno da zona colonial italiana.
\end{abstract}

Palavras-chave: Imaginário social. Imigração italiana. Etnicidade.

* Professor do Curso de História na Ulbra e Professor na Facoltà di Lingue e Letterature Straniere Moderne, Università degli Studi di Bologna. Doutor em História pela UFRGS.

Anos 90, Porto Alegre, v. 12, n. 21/22, p.271-294, jan./dez. 2005 
Conquista da terra e civilização do gentio...

As imagens que são construídas acerca dos processos imigratórios têm marcas profundas nas construções mnemônicas de descendentes dos primeiros imigrantes, constituindo-se em verdade para o grupo étnico, pois se vinculam sobretudo às falas de memorialistas e associações internas ao grupo. Essas elaborações tornam-se objeto de identificação positiva nas comunidades, sendo elementos que a distinguem como coletividade. Neste sentido, a memória sobre o processo imigratório no sul do Brasil forjou, ao longo desses 130 anos de imigração italiana, a marca do imigrante como elemento civilizador/europeizador das terras devolutas do governo imperial. A rigor, percebia-se nesse egresso de terras européias a possibilidade de desenvolver econômica e socialmente essa região, ocupando os espaços "vazios". Entendido como racialmente superior, esse egresso de terras européias - branco viria dar um sangue mais saudável ao elemento nacional, purificando a nação.

De outra parte, contrariando essa construção e ao mesmo tempo mostrando seu efeito eclipsante da realidade, Piero Brunello (1994) traz à luz uma foto do período inicial do processo imigratório, deixando ver uma outra face da realidade na terra de imigração. $\mathrm{O}$ autor apresenta uma foto de imigrantes trentinos que retornam de uma caçada e apresentam seus troféus de guerra, entre animais mortos e bens apreendidos, entre os quais podem ser percebidas duas crianças indígenas - as quais eram prisioneiros de guerra. ${ }^{1}$ Certamente, se essas crianças foram trazidas é porque seus pais já não existem mais, tendo sido vítimas de uma "guerra" de ocupação, diante de comunidades indígenas instaladas na região.

Essa fotografia que se encontra no livro de Brunello, acima citado, a qual terá fragmentos reproduzidos, também, na capa e contra-capa da obra, ilumina uma outra relação entre o imigrante italiano, especialmente setentrional, e a população autóctone. Ao analisar-se com mais atenção o conjunto da imagem, percebe-se dez homens, todos de casaca e de chapéu, representação de um

Anos 90, Porto Alegre, v. 12, n. 21/22, p.271-294, jan./dez. 2005 
formalismo de dia de festa. Afinal, o retorno da caçada é uma festa na comunidade, comemora-se as aquisições da luta. Apenas um dos homens não possuía barba e/ou bigode, costume que denota maturidade e sobriedade. A inexistência de imberbes cria a aparência de que não se encontravam jovens entre eles, mas sabese que, apenas possível, esses deixam crescer pêlos no rosto, buscando, assim, parecer mais velhos. ${ }^{2}$

Diante da fachada de uma cabana com porta e janela fechadas, esses dez homens estão dispostos enfileirados, um ao lado do outro, todos com algum tipo de espingarda na mão; aqueles que não empunham a arma, colocam a mão na pistola que se encontra na cintura, como a demonstrar os instrumentos que proporcionaram aquele triunfo da civilização. $O$ único que não tem sua mão segurando uma arma ou que não está apoiado em uma arma é, bem no centro, um alto e magro imigrante que traz nos braços uma criança indígena chupando as mãos. Completam a composição da fotografia cestos, potes, colares e instrumentos de guerra colocados à frente do grupo, certamente tomados dos indígenas atacados. Nesse mesmo patamar dos utensílios capturados são colocadas duas outras crianças indígenas, uma delas com a barriga inchada.

Essas crianças apresentam uma imagem de pânico, depreendida tanto de suas faces quanto da posição de seus braços. Os rostos terrificados apresentam um misto de olhares, entre o assustado e o envergonhado, enquanto que os braços cruzados de uma criança estão dispostos como a cobrir o corpo; em outra, a mais velha, representam essa busca de proteção em um ambiente de todo desconhecido. Percebe-se, assim, um contraste entre o pavor que expressam as feições dos indígenas e a marca da vitória e da conquista estampada na face dos "conquistadores" trentinos. 


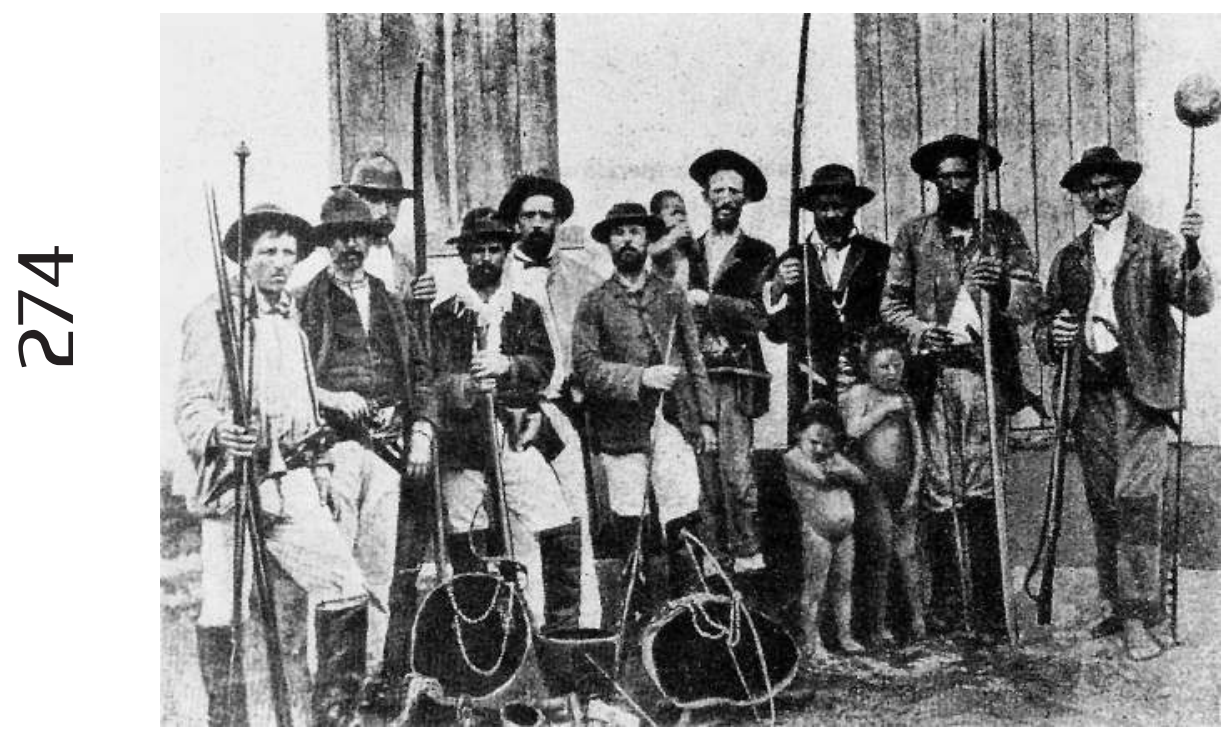

Figura 1 - Ritorno di una battuta. Trofei e prigionieri (1883). Fonte: Brunello, 1994.

A civilização impunha-se à barbárie, chegando com botas longas e chapéu, em expressão de poder e força, além de em uma posição distinta na sociedade. Porém, cabe o questionamento de qual representação de civilidade estava implícito nessas incursões de imigrantes pela floresta na busca da ocupação, ou ainda, que imagem se cristalizava - no imaginário dos recém chegados - dessas populações autóctones, qual era o grau de humanidade atribuído a elas. Mesmo não se tendo a resposta para essas questões, é importante manter a discussão sobre esses processos de trocas entre os imigrantes e as comunidades aqui existentes quando de sua chegada, e que percepção eles estavam construindo da diferença.

Todavia, na dinâmica de reelaboração desse processo imigratório, em especial entre os grupos de descendentes de imigrantes italianos no Rio Grande do Sul, a produção está concentrada na área de um certo pensamento antropológico, e é conduzida por grupos genealogicamente envolvidos com o processo em si. $\mathrm{Na}$ 
leitura desses grupos, bem como nas demais produções sobre a imigração italiana na região sul, a imagem das crianças indígenas como troféus de guerra, ou mesmo a existência da referida foto não é alvo de discussão. $\mathrm{O}$ autor mesmo comenta esse esquecimento, vinculando-o à narrativa de uma determinada epopéia da imigração:

Sobre o argumento existe uma censura, a qual é devida a um tipo de mito da fronteira, que idealiza a figura do colono e remove ou torna falso os aspectos que podem ofuscar

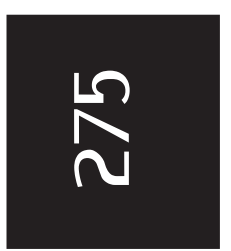
a epopéia. (Brunello, 1994, p.VIII).

Com essa argumentação, Brunello passa a discutir um processo de mitificação do fenômeno imigratório no sul do Brasil, apresentando uma face menos civilizada desses egressos da Península Itálica. Nesse sentido, pode-se entender como um tipo específico de leitura sobre a imigração esse conjunto de produções que desde o cinqüentenário do processo imigratório enaltece os feitos do colono italiano como produtor de civilidade nessas terras incultas ou mal cultivadas do Rio Grande do Sul. Assim, denota-se que esse processo construído pelos estudiosos da imigração, ao longo dos últimos oitenta anos, não é falso, porém, não traduz em sua pluralidade as vivências e as relações estabelecidas pelos imigrantes italianos em solo gaúcho, apresentando uma parcela do processo, como se fosse o todo.

A rigor, a literatura sobre a imigração produzirá figuras emblemáticas no processo de ocupação do solo, as quais serão elementos de identificação, a partir de uma vontade mágica de pertencimento:

O meio mercantilizado e estereotipado da cultura de massa se constitui de representações e figuras de um grande drama mítico com o qual as audiências se identificam, é mais uma experiência de fantasia do que de autoconhecimento. (Sovik, 2003, p.12). 
Conquista da terra e civilização do gentio...

De qualquer forma, é relevante discutir tanto o contexto de construção desse imaginário da imigração italiana quanto os elementos constitutivos do início de tal processo. Para esse intuito, dois elementos se entrecruzam, a busca da construção de uma identidade nacional marcada pelo elemento branco e o festejo das conquistas do imigrante nos primeiros cinqüenta anos de trabalho em terras brasileiras.

O processo de construção de uma identidade nacional no Brasil desde o segundo quartel do século XIX baseava-se, fundamentalmente, na negação de uma marca de africanidade, ou seja, de negritude. A imagem de nação que se configurava, especialmente a partir do Romantismo, tanto no Instituto Histórico e Geográfico Brasileiro - IHGB - quanto na Academia de Belas Artes, bem como no ensino em geral, era de um cruzamento do branco português com o bom selvagem nacional. Logo, desde o início, a marca por excelência que se buscava dar à identidade brasileira era de branquitude (Schwarcz, 1998).

Entretanto, no transcorrer do século XIX a idéia de um nacionalismo cultural vai sendo suplantada por uma construção de identificação nacional marcada pela raça. Giralda Seyferth (1996) destaca que a importância de um nacionalismo demarcado pela língua e pelas tradições populares nacionais passa a ceder lugar a uma descoberta do racismo, radicalização do darwinismo social e origem da eugenia. Na esteira dessa transformação, ver-se-ão, ao longo do último quarto do século XIX, grandes levas de imigrantes europeus aportarem em terras brasileiras. Essa massa populacional deslocou-se fortemente impulsionada por uma agressiva política imperial de aliciamento, a qual foi implementada em todo o continente Europeu.

Ancorada na Antropologia Física e idealizada por personagens como Gobineau, Chamberlain e Lapouge, a determinação da superioridade racial branca percebia a mestiçagem de forma negativa. Entretanto, a intelectualidade brasileira, frente a essa tese da 
inferioridade do mestiço, construiu a teoria de um branqueamento em três gerações, o qual produziria uma população branca. Nesse intuito, elaborou-se um plano de regeneração nacional, a partir da vinda de imigrantes selecionados. Será nesse contexto de uma intrínseca superioridade branca que se dará o desembarque desses italianos, tanto em São Paulo quanto no Rio Grande Sul, sendo também esse o pano de fundo do período de festejo do qüinquagésimo aniversário da imigração italiana.

A partir de 1878, ter-se-á uma forte e direta atuação da pro-

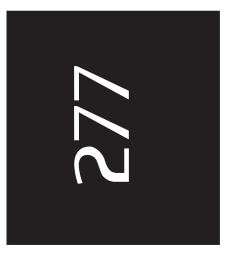
víncia de São Paulo na arregimentação de imigrantes. Antônio Queiroz Teles, visconde de Parnaíba, nesse ano governador da província de São Paulo, após percorrer vários países, irá optar pela busca de imigrantes italianos. Assim, constituiu, sob sua presidência, a Sociedade Promotora de Imigração, em 1886. No período entre 1886 e 1888, essa Sociedade introduziu no Brasil 17.856 famílias, perfazendo um total de 101.396 pessoas, participando desse "boom" imigratório de finais do século XIX. Mesmo assim, será a última década do século uma das mais expressivas no que se refere à chegada de imigrantes italianos em solo brasileiro:

Em 1891 sobe a 84.486, seguindo três anos de menor movimento, até que em 1895 a imigração italiana alcançou o apogeu, registrando a entrada de 106.526 pessoas. Em 1896 a corrente imigratória italiana, por si só, representava quase o dobro das demais, e dois anos depois, em 1898, mais da metade da imigração é ainda de procedência italiana, verificando-se o mesmo nos dois anos que se seguem. (Cenni, 2003, p.219).

Será no bojo dessa percepção de sociedade, construída em finais do século XIX, que se dará a grande onda imigratória de europeus para o Brasil. Dentre os tipos possíveis, será o italiano, por suas semelhanças lingüísticas e religiosas, o mais requisitado 
Conquista da terra e civilização do gentio...

para esse processo de purificação do elemento nacional. Efetivamente, os cinqüenta anos que se passam entre o início da imigração e as festividades de 1925 são marcados por uma progressiva positividade do elemento branco/europeu, logo, de uma visão de sua presença enquanto fomentador de civilidade para a nação.

No caso específico do Rio Grande do Sul, o imigrante italiano será percebido como aquele trabalhador incansável que está construindo a grandeza e pujança do estado. ${ }^{3}$ Certamente, os traços psicológicos atribuídos a essas populações da Península Itálica têm uma relação direta com o progresso econômico que se começa a perceber na região a partir do início do século XX.

Quando se fala na construção de uma memória sobre a imigração italiana, em absoluto entende-se que essa parte de algo inexistente, ou que é desde sua base uma construção fantasiosa. Tem-se presente que a contínua elaboração dessa imagem positivada do processo imigratório reside em traços reais do percurso, os quais, progressivamente, são tecidos como uma epopéia, o grande êxodo para a terra prometida. Assim, são destacadas essas marcas de sofrimento e trabalho árduo para transformar uma terra inóspita e virgem em um potente centro produtivo, ressaltando sempre que a nobreza da raça italiana foi produtora desse núcleo de civilidade no coração da floresta.

A narrativa que se consagrou sobre a trajetória dessas famílias vêneto-lombardas e trentinas para a região sul do Brasil parte de uma conjuntura de miséria absoluta em solo italiano e de uma necessidade brasileira de povoamento dos espaços vazios. Dessa forma, na província de São Pedro, em 1870, são criadas as colônias imperiais de Conde d'Eu e Dona Isabel, ambas já na região serrana. Ainda em 1868, algumas famílias alemãs procuraram ocupar essas terras das referidas colônias; porém, as dificuldades de comunicação e as disputas com os índios fizeram com que o projeto fosse abortado, tendo eles abandonado Conde d'Eu. 
Outros grupos continuam chegando ao longo da década de 1870, formando, ainda, a colônia de Campo dos Bugres. Para chegar aos núcleos coloniais, depois do trajeto até Porto Alegre e da espera para seguir viagem, os imigrantes poderiam seguir por dois caminhos: (1) dirigiam-se por barco até Montenegro e, depois, subiam por picadas até Conde d'Eu e Dona Isabel; (2) dirigiam-se por barco pelo Rio Caí até Porto Guimarães, seguindo, após, por picadas até a região de Nova Palmira e Campo dos Bugres.

A dimensão da viagem, já em solo brasileiro, é outro elemen-

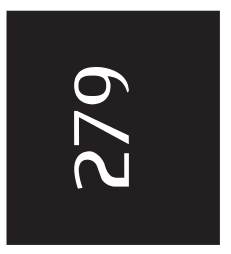
to que torna grandiosa a epopéia, pois marca as dificuldades de penetração em meio à floresta, o desafio dos animais, os diversos dias de deslocamento. Ao mesmo tempo, produz como que um rito de passagem, pois vai introduzindo os imigrantes na nova realidade. Devido à dificuldade de comunicação entre o mundo que é deixado para trás e o novo que se apresenta, a trajetória terrestre desses imigrantes pode ser entendida, também, como a passagem por um portal que os conduz a um mundo desconhecido e primitivo, no qual devem aprender a sobreviver.

Com o florescimento das colônias, já no início do século XX, casas em pedra, com ou sem reboco, começaram a ser construídas: marcadas ainda estavam as características arquitetônicas das regiões de procedência. A tradicional casa colonial vêneta de dois ou três pisos pode ser vista nas mais diversas localidades de colonização italiana na serra gaúcha. Construída em três andares, a habitação era constituída de uma cantina no andar inferior, de uma zona diurna no nível intermediário e de uma zona noturna no último piso.

O andar mais baixo da moradia, muitas vezes abaixo do nível do terreno, servia para a conservação dos gêneros alimentícios, tais como queijos e salames, bem como para a produção do vinho. Imediatamente acima, tinha-se o espaço da vida social familiar e comunitária - era o lugar da cozinha e da "sala de estar", onde a família se encontrava durante o dia e onde se recebiam os 
Conquista da terra e civilização do gentio...

visitantes, especialmente nas noites de filò. ${ }^{4} \mathrm{O}$ terceiro piso era onde se encontravam os quartos, era uma zona mais reservada e íntima da casa.

Algumas moradias, especialmente aquelas feitas em madeira, tinham a cozinha em um espaço fora da casa, construído a uma certa distância. Isso se devia grandemente ao perigo de incêndio que a precariedade dos antigos focolare ${ }^{5}$ trazia. Assim, a distância entre a cozinha e a habitação permitia uma segurança maior à família quando da utilização do fogo.

O espaço doméstico, além de ser o lugar da vida familiar do imigrante, também é, por excelência, o locus da rememoração das experiências da trajetória da família e do grupo étnico. No interior da residência, as histórias coletivas são reinventadas e o mito civilizador da imigração italiana é edificado. Dessa forma, os preceitos religiosos são mantidos e enriquecidos pelos rituais quotidianos de orações, invocações, súplicas e ladainhas e a trajetória da imigração vai sendo revisitada, especialmente a partir das aventuras de Nanetto Pipetta. ${ }^{6}$

Será a partir do jornal Staffetta Riograndense - de propriedade dos Frades Menores Capuchinhos ${ }^{7}$ - que se terá um dos eixos para construção de uma determinada memória acerca da imigração italiana no Rio Grande do Sul. Nele, como já enunciado, começava a entrar na casa dos descendentes, ao longo da década de 1920, a figura de Nanetto Pipetta, o qual vai se constituir em figura emblemática dos imigrantes vênetos no sul do Brasil.

Muito embora fosse pequeno o número de imigrantes que tinha acesso à leitura do jornal e, conseqüentemente, contato com a leitura da história de Nanetto, sua popularidade era grande na comunidade de descendentes de italianos na serra gaúcha. Segundo Adriana Orlandi (2000), esse processo de popularização do personagem dá-se pela transformação dos leitores em multiplicadores na comunidade. Assim, Nanetto é incorporado à tradição oral, pois muitos o conheceram somente a partir da 
oralidade. Nesse sentido, as aventuras de Nanetto Pipetta transformam-se em storie, em fábulas contadas oralmente na comunidade nos mais diversos momentos de sociabilidade, do espaço da piazza àquele do filò.

Essa produção literária da zona colonial italiana, ${ }^{8}$ para além de ser instrumento de diversão, um passatempo na comunidade, adquire um sentido de militância na manutenção de uma identidade contadina vêneta:

[...] o caráter de militância dessas publicações ${ }^{[0]}$ se dá no sentido da defesa e da valorização do universo camponês de origem vêneta, que procura manter viva uma imagem e uma memória, para adaptá-la às novas circunstâncias. O vêneto torna-se o lugar por excelência da memória coletiva, pois corresponde ao patrimônio de sentimentos, crenças, estereótipos, que caracteriza o camponês vêneto, transferido para o outro lado do oceano. ${ }^{10}$

Assim, o Vêneto sofre um processo de desterritorialização e destemporalização, transformando-se em uma imagem idílica e flutuante na imaginação dos egressos da Península Itálica, nem sempre provenientes dessa região, mas que se associam a essa imagem do imigrante Nanetto Pipetta. Essas obras marcam a reelaboração além-mar de bens culturais não-tangíveis trazidos com os imigrantes, os quais vivificam uma identidade étnica.

A literatura da imigração torna-se um elo de identificação comunitária, trazendo em si perdas e esperanças. Por um lado, marca a nostalgia das coisas que foram deixadas para trás, de um mundo que não está mais no horizonte de expectativas. Porém, por outro elabora um sentimento de reconstrução, a possibilidade de iniciar mais uma vez e, de uma forma melhor, ressignificar esse mundo perdido. Afinal, se está trabalhando com uma imigração que deu certo e na qual muitos construíram capital e adquiriram um pedaço de terra, enfim, viveram o seu sonho de ascensão social. 
Conquista da terra e civilização do gentio...

Ao mesmo tempo, essa produção literária não deixa de ter uma intencionalidade produtiva, um núcleo intelectual que pensa essa relação de identificação e busca marcar, de uma forma determinada, a identidade comunitária. Nesse sentido, divulgadas e produzidas por setores vinculados à Igreja, especialmente instalados no seio da congregação dos Frades Menores Capuchinhos, as obras literárias sobre a imigração buscam elaborar no grupo de descendentes italianos uma imagem que integre um catolicismo intransigente e uma forte cultura rural, entendidos como caracterizadores de uma identidade vêneta.

De qualquer forma, essa identificação com o personagem de Nanetto Pipetta - ou de seu irmão, não tão famoso, Nino - é parte da construção de uma comunidade de sentidos entre o grupo de descendentes e o texto literário ou a transmissão oral. A narrativa adquire popularidade porque as pessoas nela encontram sua história, entendem-se como parte dessa trajetória vivida por Nanetto, independente de seus ancestrais a terem experimentado ou não. A literatura de imigração cativa o público não apenas pela linguagem dialetal que ressoa como um eco da infância, mas pela capacidade evocativa da memória, marcada por um vínculo afetivo de recordação do grupo de pertença.

Pipetta torna-se um elo nessa tessitura de uma cadeia de pertencimento afetivo que não permite o esquecimento: "Portanto, a memória não faz ruptura entre passado e presente, porque só retém do passado aquilo que ainda está vivo ou capaz de viver na consciência do grupo que a mantém" (Orlandi, 2000, p.84).

Com isso, desenvolvia-se no espaço doméstico a dinâmica da rememoração. O interior da casa era um lugar privilegiado da construção de uma memória sobre a imigração, tanto nos momentos de intimidade da família quanto naqueles de sociabilidade com os grupos familiares próximos. A zona "pública" do lar será o centro de trocas e, dessa forma, de construção imagética da comunidade de imigrantes, de sua cultura rural e de suas práticas religiosas.

Anos 90, Porto Alegre, v. 12, n. 21/22, p.271-294, jan./dez. 2005 
Embora não se possa, segundo Iam Chambers, retornar à casa, àquela cena primária cristalizada no passado, pode-se vislumbrála a partir de sinais por ele emitidos, os quais permitem a reelaboração de uma teia que o significa:

Diante da "floresta de signos" (Baudelaire), nos encontramos sempre na encruzilhada com nossas histórias e memórias ("relíquias secularizadas", como Benjamin, o colecionador, as descreve) ao mesmo tempo em que esquadrinhamos a constelação cheia de tensão que se estende diante de nós, buscando a linguagem, o estilo, que vai dominar o movimento e dar-lhe forma. Talvez seja mais uma questão de buscar estar em casa aqui, no único momento e contexto que temos. (Chambers apud Hall, 2003, p.28).

Essa memória construída acerca da imigração funcionava como uma sinalizadora de um efeito de unidade entre passado, presente e futuro. Elaborava-se, a partir do reagrupamento das relíquias de um passado comum, uma trajetória de auto-conhecimento enquanto grupo, possibilitando a percepção de elos comunicantes que justificavam a experiência da expatriação e significavam a caminhada na terra de chegada. Isso, ao mesmo tempo em que funcionava como pontes entre o paese distante e a atualidade da vida na nova terra.

Acresce-se à literatura, enquanto construrora de uma percepção da imigração, a música, também parte desse sustentáculo imagético da operosidade do colono italiano, no estado, de sua dedicação ao trabalho. Como diz uma das canções mais célebres da imigração, Mérica Mérica, nas dificuldades foram construídas indústrias e fundadas cidades:

$\mathrm{Na}$ América nós chegamos, não encontramos nem palha nem feno, dormimos sobre o terreno nu, como animais nós repousamos. 
Conquista da terra e civilização do gentio...

A América é longa e é larga

Ela é formada de montes e de planícies

e com a indústria de nós italianos

fundamos paese e cidades. (CIBAI..., 1972, p.16).

A canção não deixa de ser fruto de um processo de revisão da trajetória da imigração, enfatizando o ponto de chegada, ou seja, a vitória. Mérica Mérica expressa a celebração da conquista da terra - de uma certa forma comemora-se o encontro da terra da cuccagna, mesmo invertendo o preceito do não trabalho envolto no mito. De qualquer forma, ela apresenta uma absolutização do bom termo do processo emigratório, como uma justificação pelo deslocamento. Dessa forma, a canção pode ser percebida como uma narrativa epopeica do fenômeno migratório, haja vista que em sabendo o desfecho, é possível "tragediar" o percurso, valorizando o seu final.

Essa música, destacada enquanto um dos principais símbolos da imigração italiana, presta-se a duas análises complementares, ou melhor, sofre um processo de estetização do vivido e, ao mesmo tempo, cria um efeito Gershwin. ${ }^{11}$ No primeiro ponto, a história enquanto experiência quotidiana da comunidade, ao ser narrada, é estetizada enquanto ficção. No segundo, a canção que se torna elemento emblemático do processo imigratório passa a construir verdade e, dessa forma, constrói um universo no qual os descendentes se reconhecem e se sentem à vontade, independentemente da verdade; elabora um efeito de verdadeiro, de autoidentificação para o grupo de descendentes.

Certamente, não se encontra na memória sobre a imigração, especialmente nos álbuns comemorativos, tanto nesse do cinqüentenário quanto nos outros dois álbuns produzidos, dos setenta e cinco anos e dos cem anos da imigração, a imagem dos imigrantes que não "deram certo", aqueles que se depararam com a doença e, desesperados, imploravam para retornar à terra natal, o que se pode perceber em cartas de diversas famílias (Franzina, 1980). Como

Anos 90, Porto Alegre, v. 12, n. 21/22, p.271-294, jan./dez. 2005 
momento de festa, a imagem que se quer construir é de um mundo rural, ainda vinculado à Itália, e de uma vitalidade e pujança econômica e moral.

Nesse sentido, encontra-se sobremaneira o destaque das famílias que construíram já nesses primeiros cinqüenta anos uma estabilidade econômica, e lista-se minuciosamente as empresas que estão fortemente se desenvolvendo. Nas pequenas cidades que começam a despontar, especialmente após a inauguração da linha férrea, ressaltam-se as obras de civilidade que foram sendo realizadas, acima de tudo, a construção da Igreja matriz, as praças, as ruas que começam a ter definido seu traçado.

Porém, destacam-se como particular diferença na construção dessa memória sobre a imigração as perspectivas rural e urbana, sendo a primeira destacada nas publicações capitaneadas pela Staffetta Riograndense e, a segunda, pelas produções relativas ao cinqüentenário da imigração italiana. Enquanto no jornal católico prevalecia a imagem da vitória de um Vêneto católico e campesino, nas publicações do festejo da imigração são destacados o crescimento econômico e as organizações comerciais, industriais e associativas que despontam.

A própria casa, ou melhor, a posse de uma moradia era objeto de um sonho acalentado desde a partida da Itália, pois a grande maioria dos imigrantes alugava terras para o trabalho antes de emigrarem. Então, possuir seu próprio chão, seu campo, sua casa, sua colheita foi um dos propulsores para esse abandono da terra pátria. No novo continente, ter a posse efetiva da terra é um justificador da partida. Afinal, rumava-se à "terra prometida", o que traz, mais uma vez, a dimensão vivencial do êxodo, mas a partir do olhar de quem efetivamente tomou posse da "promessa de Deus" (Beneduzi, 2004).

Além dessa busca pela posse da terra, pode-se perceber, como outra característica na tentativa da ascensão no meio italiano, a imagem da poupança - que se constitui em elemento simbólico 
Conquista da terra e civilização do gentio...

fortemente destacado nas comemorações de 1925 e 1975. Na medida em que os negócios começavam a ser feitos, que se iniciava o escoamento da produção, desenvolvia-se um esforço de poupança que marcará as famílias imigrantes e que possibilitará, em alguns casos, o surgimento de pequenas indústrias domésticas e seu posterior desenvolvimento. Isso contribuirá para a construção da imagem do colono laborioso e dos imigrantes que "deram certo", quando do festejo da italianidade, no cinqüentenário da imigração, em 1925.

Para esse fim, especialmente sobre a ótica do imigrante que "deu certo", é exemplar o compêndio produzido como marca dessa comemoração do cinqüentenário da imigração - Cinquantenario della colonizzazione italiana nel Rio Grande del Sud - referendado tanto pelo Duce italiano Benito Mussolini, quanto pelo então presidente do estado do Rio Grande do Sul, Antônio Augusto Borges de Medeiros, como sinal do crescimento gaúcho com a mão do industrioso colono italiano. O chefe do governo nacional, como assim se declara Benito Mussolini na carta de abertura do livro comemorativo, destaca a bravura do emigrante como marca da "inteligente operosidade da Pátria", expressando sua solidariedade de trabalhador e italiano. Destaca a produtividade do emigrante em solo brasileiro e sua contribuição no estreitamento dos laços entre os dois países:

No nobre orgulho que eleva as vossas almas, enquanto parais para contemplar os resultados da longa e tenaz fadiga, [...] me sinto orgulhoso de mandar a minha saudação a vós, que assim nobremente tendes contribuído para valorizar as férteis terras que vos acolhem e a unir em amizade a Itália e o Brasil. (Cinquantenario..., 1925, p.19).

Os próprios termos utilizados, tanto no motivo da comemoração - colonização italiana - quanto no título da obra - cooperação para o progresso civil e econômico - mostram qual a imagem

Anos 90, Porto Alegre, v. 12, n. 21/22, p.271-294, jan./dez. 2005 
da emigração que se quer construir em uma Itália desejosa de vencer as dificuldades da Primeira Guerra Mundial e construir um forte nacionalismo em torno ao Duce. Também, dá conta da mudança que se procura fazer na imagem do emigrante, o qual abandona a pátria por nela não poder sobreviver e, parafraseando Josué Guimarães, a "ferro e fogo" constrói a riqueza do local no qual se instala.

Outro fator que se deve destacar neste momento é a positivação da identidade étnica. $\mathrm{O}$ aumento nos processos de troca entre imigrantes e nacionais traz à luz elementos culturais diferenciadores, como a língua, os comportamentos sociais, a percepção do trabalho e da poupança, incrementando a percepção de uma diferenciação étnica. Nesse sentido, ressaltar os elementos positivos da vinda do imigrante italiano para o Rio Grande do Sul é uma forma de demarcar essa comunidade de iguais.

O jornal $A$ Federação também destaca essa positividade da imigração italiana, salientando a comunhão que se faz entre a Itália e o Rio Grande do Sul, perpetrada pelo laborioso egresso da Península. Em discurso de 1918, o intendente de Garibaldi fala à Comitiva da Embaixada da Itália, em uma sua passagem pelo município:

Excelentíssimo Senhor Embaixador, podeis ver, e eu desejarei que vossa retina gravasse indelevelmente, o efeito maravilhoso das duas bandeiras, em nossa frente entrelaçadas, fulgindo em suas cores históricas, mas trançadas por uma cor comum, a verde, de modo que não se sabe onde uma começa nem onde a outra termina! (A Federação, 1918).

A idéia de operosidade do imigrante italiano está em sintonia com a identidade regional que se procura forjar, pois se constrói ao mesmo tempo a figura do gaúcho como um desbravador e lutador, mantenedor das fronteiras da nação frente às inúmeras tentativas estrangeiras de transpô-las. Essa nova memória festiva da 
Conquista da terra e civilização do gentio...

presença italiana vem ainda ao encontro da política fascista de construção da forte Itália. Nessa perspectiva, repensar a experiência emigratória como uma exportação de civilidade muito colabora na elaboração de uma Itália pujante no concerto das nações, em uma Europa ainda egocêntrica. Contrapõe-se, dessa forma, a idéia de uma nação fraca e pobre que não pôde manter e sustentar os seus "filhos".

Soma-se a essa carga de positividade a visão de uma superioridade ou inferioridade intrínsecas à etnia/raça, segundo a concepção histórico-cultural de finais do século XIX e das primeiras décadas do XX. Com isso, a comemoração traz em si a missão de regeneração da sociedade, atribuída à imigração, e o elemento italiano como parte formadora de um tipo racial mais apto que o brasileiro. O próprio livro do cinqüentenário ressalta essa perspectiva, lembrando, inclusive, Oliveira Vianna, ao comentar o processo de branqueamento no Brasil e as circunstâncias especiais vividas no Rio Grande do Sul em decorrência do fenômeno imigratório:

Na composição étnica da nossa população, como na formação do nosso definitivo tipo racial, hoje ainda em elaboração, teve e continua a ter a imigração uma influência que, notavelmente desde o início, termina por tornar-se fator preponderante de transformação. No Rio Grande do Sul, o fenômeno, muito acentuado, reveste-se de circunstâncias especiais, que excluem o cruzamento com raças inferiores, verificando-se em outras regiões do país. (Cinquantenario..., 1925, p.245).

Ao mesmo tempo, está-se construindo uma outra imagem sobre a terra de partida, ou seja, da negatividade do momento em que se abandona o mundo pátrio: está-se reconstruindo o processo a partir da positividade de uma Itália colonizadora e civilizadora. Esse discurso pode ser percebido já quando, do início da experiên-

Anos 90, Porto Alegre, v. 12, n. 21/22, p.271-294, jan./dez. 2005 
cia emigratória, no século XIX, pelo posicionamento do deputado Giovanni Bovio, na Câmara, ressaltando que os italianos, amantes do trabalho, tinham o dever de "colonizar aquela parte do Brasil que ainda é habitada de homens primitivos, que ignoram os imensos tesouros que oferecia a cultura daquela floresta virgem". ${ }^{12}$ Brunello (1994) ainda destaca a não-existência de um conceito diferenciado para a colonização na Eritréia ou no Sul do Brasil, sendo essa idéia dúbia fundada sobre a potência da nação e a superioridade racial européia.

Entende-se relevante destacar que, ao se enunciar esse processo de construção de uma memória sobre a imigração italiana, está-se trabalhando essencialmente com intelectuais e aqueles egressos que conquistaram uma posição de prestígio na sociedade, ou seja, quem está marcando o festejamento são aqueles imigrantes que "deram certo" e que estão incluídos em um projeto de Grande Itália. Serão esses self made men apresentados no livro comemorativo ao cinqüentenário da imigração, como Aristides Germani e Abramo Eberle, os grandes patrocinadores de uma memória a ser preservada, a qual, no dizer de Crocetta, lembra que esses imigrantes, embora constituindo $7,9 \%$ da população do Rio Grande do Sul e possuindo apenas a quadragésima parte do território do estado - a mais acidentada -, são responsáveis pela produção de setenta porcento dos grãos e possuem metade dos estabelecimentos industriais (Cinquantenario..., 1925, p.456).

Essa terceira geração sofrerá de uma forma mais intensa o processo de interação com membros de outras etnias, pois os meios de transporte já permitem uma maior circulação de mercadorias e, obviamente, de idéias. Assim, o aumento das trocas, concretas e simbólicas com alemães, poloneses, brasileiros e outros, levará a um "pensar quem somos" em meio a esses outros. O que até então era um fazer mecânico, pois marcado pelos iguais, tornar-se-á ponto de reflexão frente àqueles que não somos. A alteridade marcará essa positividade identitária que se quer construir na zona de imigração italiana da serra gaúcha.

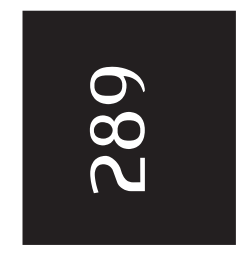


Conquista da terra e civilização do gentio...

Nesse sentido, a produção do álbum do cinqüentenário, bem como toda a comemoração que se desenvolveu no ano de 1925 e em seu entorno, buscavam glorificar o imigrante italiano, destacando três elementos essenciais a essa identidade em construção: religião, família e trabalho. Essas três facetas da italianidade nortearão os discursos comemorativos, podendo ser percebidas em todos os capítulos da obra comemorativa e nos discursos sobre sua contribuição no Rio Grande.

Como se pode perceber, a dinâmica da comemoração produziu, a partir de famílias singulares, que "deram certo", uma memória sobre a imigração italiana, fundada basicamente no catolicismo e levada adiante por religiosos, particularmente no seio das famílias. Como parte do processo imigratório para o Rio Grande do Sul, em um período diferente, italianos se associam a açorianos, alemães, poloneses, suíços, austríacos e muitos outros como parte formativa do estado, também construindo a sua caminhada do Egito à Terra Prometida, ressignificando a história do seu Êxodo. Nisso, a partir da tomada da terra e do início de sua ocupação foise construindo a posteriori uma imagem justificadora do processo de travessia do oceano, qual seja, a redenção: "vim, vi e venci".

Dessa forma, a geração de 1920, da qual grandes expoentes nasceram já em solo brasileiro, redescobrirá o fenômeno imigratório, cobrindo-o com um véu de positividade, tanto justificador da trajetória, do abandono pátrio, quanto construtor de uma percepção enquanto grupo étnico, a partir da positiva função civilizadora. Nesse discurso, o imigrante passa a ser visto mais como aquele que constrói a pujança do Rio Grande do que como aquele miserável que abandona o solo pátrio. $\mathrm{O}$ processo imigratório se ressignifica a partir da descoberta de uma missão divina de civilizar e tornar produtiva a terra prometida por Deus. Mesmo Nanetto, funcionando como a alteridade do anti-herói, permitirá a leitura do verdadeiro bom imigrante.

Anos 90, Porto Alegre, v. 12, n. 21/22, p.271-294, jan./dez. 2005 
Tem-se presente que a discussão sobre esse lugar de memória que se constituiu o "mito civilizador" na imigração sulrio-grandense envolve dois fóruns específicos: a quotidianidade do imigrante e a representação construída por uma elite colonial econômica e/ou intelectual. Porém, partindo também de elementos vivos na experiência diária dos imigrantes, embora obliterando a diferença, a representação mitificada do processo imigratório constituir-se-á enquanto a realidade acontecida.

Nesse sentido, embora o real passado apresentasse uma

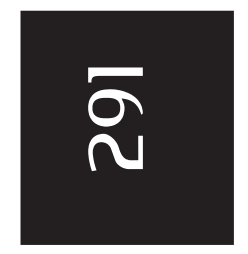
multiplicidade de relações, próprias da dinâmica dos grupos sociais, a memória que se construiu ao longo do processo vincula-se a uma representação elaborada por essa elite que se formava entre os recém-chegados. Esta passa a ser entendida como a verdade do fenômeno imigratório, porque constrói uma comunidade de sentidos para com o grupo de representados, os quais se enxergam positivamente. Outrossim, essa mitificação do processo tal qual é dada a conhecer associa-se a uma identidade regional que se encontra impulsionada por um forte vento criativo no período de 1930-1940.

Conquest of land and civilization of natives: the Italian immigrating phenomenon in Rio Grande do Sul

Abstract. In this study we intend to discuss the imagetic constructions of civility that established the imaginary of Italian immigration in Rio Grande do Sul. We will especially focus on the frontier myth, that presents the image of a good Italian immigrant worker and social partner in the state development. In dialogue with this representation, we use three levels of documents: the Catholic literature about the immigration - through Nanetto Pipeta"s book, the immigration song Mérica Mérica, and the book that celebrates the 50th anniversary of Italian immigration and colonization in Rio Grande do Sul. We realize that this image constructed by the contacts with Brazilians and with other Europeans - albeit an ethnic reading of the real - established itself as the truth about the past, without presenting the diversity and multiplicity of the relationship inside of the Italian colonial zone.

Keywords: Social imaginary. Italian immigration. Ethnicity. 
Conquista da terra e civilização do gentio...

\section{Notas}

${ }^{1} \mathrm{Na}$ introdução do livro Gli italiani in Brasile e il mito della frontiera, Brunello informa que essa foto foi retirada de um livro sobre a história de um paese trentino, encontrando-se abaixo da fotografia o escrito "Gruppo di trentini in Brasile - 'Ritorno di una battuta. Trofei e prigionieri' (1883)".

${ }^{2}$ Lilian Schwacz (1998) discute a representação positiva da barba na sociedade do século XIX, a partir da figura do imperador D. Pedro II.

${ }^{3}$ A figura do trabalhado incansável não é apenas marca da imigração italiana, constituindo-se também em referência positiva da identidade "alemã” no Rio Grande do Sul.

${ }^{4}$ O filó, no Rio Grande do Sul, constituía-se em um momento de descontração e lazer, acontecendo, geralmente, nas noites de sábado. Duas ou mais famílias encontravam-se em uma das casas da comunidade para jogar, conversar, comer e beber. Jogos como a bisca, o três sete, a escova eram parte dos ritos de sociabilidade, via de regra partilhados pelos homens. As mulheres conversavam, costuravam e faziam crochê na cozinha, com as crianças brincando aos seus pés. Normalmente, comiamse pinhões, crostoli, bebia-se vinho, doce, suave ou seco.

${ }^{5} \mathrm{O}$ focolare era uma espécie de fogo de chão, ao redor do qual as primeiras famílias se reunião. Dentro da cozinha, além de ser o espaço de preparação dos alimentos, também uma lugar de rememoração e partilha.

${ }^{6}$ As aventuras de Nanetto Pipetta, nascido na Itália e vindo à América para encontrar a cucagna, foram escritas por Achiles Bernardi e publicadas originalmente no Jornal Staffetta Riograndense, atual Correio Riograndense, na década de 1920.

${ }^{7}$ Os Frades Menores Capuchinhos foram trazidos pelo bispo Don Claudio Gonçalves Ponce de Leão, em 1896, para atender as comunidades italianas na serra gaúcha. Provenientes da província de Sabóia, na França, estabeleceram-se, primeiramente, na ex-colônia de Conde d'Eu.

${ }^{8}$ Além da obra citada de Nanetto Pipetta, pode-se citar, ainda, Nino - il fratello di Nanetto, Togno Brusafrati ou Storia di Peder.

${ }^{9}$ Refere-se às publicações em vêneto-riograndense, como Nanetto; Nino, il fradello; Togno Brusafrati e Storia de Peder - principais expressões de uma literatura de origem vêneta.

${ }^{10}$ ISNENGHI, Mario. Il Veneto nella America: tracce di uma letteratura popolare della emigrazione. In: FRANZINA, Emilio. Un altro Veneto: saggi e studi di storia dell'emigrazione nei secoli XIX e XX. Abano Terme (Padova): Aldo Francisci Editore, 1983 apud Orlandi (2000, p. 115).

Anos 90, Porto Alegre, v. 12, n. 21/22, p.271-294, jan./dez. 2005 


\section{Luís Fernando Beneduzi}

${ }^{11}$ Augé (2004) associa esse efeito Gershwin ao filme Um Americano em Paris para entender o efeito da cidade que busca fazer-se tal qual sua representação.

${ }^{12}$ Alessandro D’Atri, Colonizzazione nel Brasile, 1888, apud Brunello (1994, p. 70).

\section{Referências}

A FEDERAÇÃO. Porto Alegre: Museu Hipólito José da Costa, 10 ago. 1918.

AUGÉ, Marc. Rovine e macerie; il senso del tempo. Torino: Bollati Boringhieri, 2004.

BENEDUZI, Luís Fernando. Mal di Paese: as reelaborações de um vêneto imaginário na ex-colônia de Conde d'Eu (1884-1925). 2004. Tese (Doutorado em História) - Programa de Pós-Graduação em História, Universidade Federal do Rio Grande do Sul, Porto Alegre, 2004.

BRUNELLO, Piero. Pionieri; gli italiani in Brasile e il mito della frontiera. Roma: Donzelli Editore, 1994.

CENNI, Franco. Italianos no Brasil: "Andiamo in 'Merica". 3. ed. São Paulo: Edusp, 2003.

CIBAI MIGRAÇÕES ...E cantavam; coleção de cantos populares da região de imigração italiana no Rio Grande do Sul. Porto Alegre: Editora Meridional EMMA, 1972.

CINQUANTENARIO DELLA COLONIZZAZIONE ITALIANA NEL RIO GRANDE DEL SUD. La cooperazione degli italiani al progresso civile ed economico del Rio Grande del Sud. Porto Alegre: Barcellos, Bertaso e Cia.; Livraria do Globo, 1925.

FRANZINA, Emilio. Mérica! Mérica! Emigrazione e colonizzazione nelle lettere dei cotadini veneti in America Latina (1876-1902). Milano: Feltrinelli, 1980.

HALL, Stuart. Da diáspora; identidades e mediações culturais. Belo Horizonte: UFMG, 2003.

ORLANDI, Adriana. Nanetto Pipetta: representação histórica, memória coletiva e identidade nas comunidades coloniais italianas do Rio Grande do Sul. 2000. Dissertação (Mestrado em História) - Programa de Pós-Graduação em História, Universidade Federal do Rio Grande do Sul, Porto Alegre, 2000. 
Conquista da terra e civilização do gentio...

SCHWARCZ, Lilian Moritz. As barbas do Imperador, D. Pedro II: um monarca nos trópicos. São Paulo: Companhia das Letras, 1998.

SEYFERTH, Giralda. Construindo a nação: hierarquias raciais e o papel do racismo na política de imigração e colonização. In: MALO, Marcos; SANTOS, Ricardo (Org.). Raça, ciência e sociedade. Rio de Janeiro: FIOCRUZ, 1996.

SOVIK, Liv. Apresentação; para ler Stuart Hall. In: HALL, Stuart. Da diáspora; identidades e mediações culturais. Belo Horizonte: UFMG, 2003.

Recebido em 20/05/2005.

Aprovado em 02/08/2005. 